\title{
Infância, tempo e imagem: contornos para uma infância da educação
}

\section{Childhood, time and image: outlines for a childhood in education}

https://doi.org/10.34112/2317-0972a2016v34n68p13-28

César Donizetti Pereira Leite ${ }^{1}$

RESUMO: A partir de produções imagéticas de crianças de Educação Infantil, o texto problematiza os significados da infância e as questões em torno do mito pedagógico presente na Educação Infantil. Criando algumas conexões entre as imagens produzidas pelas crianças e a perspectiva de uma "prática pedagógica" na Educação Infantil problematiza-se a ideia hegemônica de um tempo cronológico na e da infância.

PALAVRAS-CHAVE: Infância; tempo; imagem; educação.

ABSTRACT: This article questions the meanings attributed to the notion of Childhood and the issues surrounding the pedagogical myth in Early Childhood Education, working from image productions of children. Creating connections between the images produced by children and the perspective of a "pedagogical practice" in Early Childhood Education, the hegemonic idea of chronological time in and of childhood is addressed.

KeYWoRdS: Childhood; time; image; education.

1. Universidade Estadual Paulista “Júlio de Mesquita Filho”, Rio Claro, SP, Brasil. 
Hoje eu atingi o reino das imagens, o reino da despalavra. Daqui vem que todas as coisas podem ter qualidades humanas. Daqui vem que todas as coisas podem ter qualidade de pássaros.

Daqui vem que todas as pedras podem ter qualidade de sapo. Daqui vem que todos os poetas podem ter qualidades de árvore.

Daqui vem que todos os poetas podem arborizar os pássaros.

Daqui vem que todos os poetas podem humanizar as águas. Daqui vem que todos os poetas devem aumentar o mundo com suas metáforas. Que os poetas podem ser pré-coisas, pré-vermes, podem ser pré-musgos.

Daqui vem que os poetas podem conhecer o mundo sem conceitos. Que os poetas podem refazer o mundo por imagens, por eflúvio, por afetos. (Manoel de Barros, Despalavra, Ensaios Fotográficos, Editora Leya, 2013)

O propósito deste texto é problematizar os significados da infância e, em particular, a forma em que ela é concebida como conjunto de sujeitos infantis de uma certa cronologia. Nesse sentido, e juntamente com um trabalho que temos desenvolvido de produção de imagens com crianças e professoras de Educação Infantil, propomos pensar com a infância no que ela nos educa para pensar - para além de uma educação da infância, acenamos para uma infância da educação.

Temos verificado em nossos trabalhos com as redes públicas de Educação Infantil que, já há algum tempo, questões sobre a infância e as práticas com a criança vêm sendo centrais nos debates políticos, nas preocupações da sociedade e nas produções acadêmicas. Observamos também que essas discussões têm, muitas vezes, se traduzido em projetos, em iniciativas e investidas de políticos, da sociedade e das universidades e têm produzido contornos de políticas públicas que chegam às escolas e às salas de aula das mais variadas e diferentes formas.

Dentro dessa perspectiva, não estaríamos exagerando se disséssemos que muito do que temos feito, nos trabalhos que desenvolvemos nas redes municipais e estaduais de Educação, tem alcançado, em muitos casos, resultados interessantes que potencializam práticas efetivas com as crianças e os professores. Mas também não seria nenhum equívoco dizer que essas políticas públicas colecionam 'fracassos' assustadores, que colocam a educação como um dos temas mais recorrentes em nossa cultura. Não iremos nos ater e ou nos preocupar com uma distinção mais precisa e definitiva entre o que seria 'sucesso' e 'fracasso' das práticas com as crianças e com a escola, pois não é o propósito aqui; vamos apenas indicar que, sendo sucesso ou 
fracasso, parece relevante que os discursos que produzimos em nosso cotidiano acadêmico acerca da infância e da educação ganham formas e percursos hegemônicos, identitários e definitivos nas ditas políticas públicas, e esses, de alguma forma, nos indicam o que e como pensar acerca das práticas com as crianças.

Salientamos ainda que muitos desses projetos, devido a suas características e dimensões, acabam criando formas e padrões determinados por 'fundamentos' específicos de áreas de saberes como a Psicologia, a Filosofia, a Sociologia, a Pedagogia, sempre postas como campos de saberes científicos e demarcadas por planos de referências, no sentido daquilo que Gilles Deleuze (2010, p. 140), apresenta como tal, ou seja, "ela renuncia ao infinito, a velocidade infinita, para ganhar uma referência capaz de atualizar o virtual", ou, dito de outra forma, é como se, ao criar as referências teóricas, conceituais, nós limitássemos as possibilidades infinitas do (e de) pensar, do (e de) criar, distanciando os executores, os educadores e a sociedade de forma geral de experiências efetivas de encontros com as crianças, como se esses "fundamentos" da educação pudessem ditar, indicar, controlar, regular e apontar os efetivos 'acontecimentos' - entendidos aqui como condições nas quais o pensamento pensa. Dito de outra forma, povoados de discursos e verdades sobre a infância e sobre o que fazer com as crianças, somos retirados de uma experiência com 'o fora', de uma experiência não definida, pois, por estar ela marcada e ancorada em um sujeito, um ser, perdemos a percepção da exterioridade, da alteridade, de uma experiência limite com a infância e com a criança.

Nesse cenário de trabalhos na educação, temos um bom exemplo nos projetos alicerçados em políticas públicas que, por vezes, transformam argumentos administrativos em argumentos pedagógicos e questões econômicas em questões acadêmicas relativas aos rendimentos escolares de alunos e também dos próprios professores. O fato é que, por mais que se diga ou faça, há problemas que continuam centrais nas experiências educativas, na sala de aula e fora dela. No estado de São Paulo, em que se inserem os trabalhos que temos desenvolvido, as políticas públicas para a Educação se pautaram, nos últimos 20 anos, em argumentos predominantemente administrativos e econômicos. Nesse cenário produziu-se uma avalanche de orientações especificamente consistentes, de um certo ponto de vista, que geraram práticas efetivas no cotidiano escolar e alinharam professores e alunos a determinados modos de discursos políticos ou acadêmicos, efetivando (mais ou menos eficientemente) modos específicos de regulação. Se tudo isso pode parecer estranho e paradoxal, ficamos com a seguinte observação: 
Infância, tempo e imagem: contornos para uma infância da educação

Eis que Agamben constata um paradoxo latente nesta situação, capaz de expor então o irremediável eclipse pelo qual atualmente passa a política: quanto menos subjetividades são formadas no corpo a corpo do indivíduo com os dispositivos tanto mais dispositivos são criados como tentativa inelutável de sujeição dos indivíduos às diretrizes do poder. Ou seja, uma vez que para o funcionamento do mecanismo operativo da política seria necessária a conflagração de sujeitos reais que nunca se configuram, a política parece ser não mais que uma forma que gira no vazio (um mecanismo oikonômico de autoreprodução), e, desse modo, encaminha-se à catástrofe. (SKRAMIN; ONESKO, 2009, p. 13-14).

Verificamos que as relações que se apresentam entre adultos e crianças ganham contornos e variantes bastante singulares em cada espaço dos diferentes momentos das experiências educativas, porém, apesar dessa pluralidade, algumas questões aparecem de forma bastante recorrente. Entre elas destacamos que, muito mais do que metodologias de ensino, nas práticas educativas o que marca e tece as relações entre professoras e alunos, entre adultos e crianças não são os sentidos produzidos, mas, sim, os modos de circulação da palavra, que passa, sobretudo e substancialmente, pela 'postura' do educador diante do educando e do educando diante do educador. Ou seja, não são propriamente os sentidos produzidos, os conhecimentos adquiridos que ganham força, mas, sim, as práticas de poderes neles manifestadas. "Creio que o que deve ter como referência não é o grande modelo da língua e dos signos, mas sim da guerra e da batalha. A historicidade que nos domina e nos determina é belicosa e não lingüística. Relação de poder e não relação de sentidos” (FOUCAULT, 2009, p. 5).

Neste campo de pensamentos, poderíamos certamente dizer que falar em infância e na criança não é propriamente a mesma coisa, mas os modos de pensar a infância e de lidar com a criança emergem em práticas de poderes, presentes nas experiências educativas (LEITE, 2007). Essas experiências, por sua vez, escapam ao suposto e desejado controle do professor, produzindo uma perda do previsível, o que sugere que as práticas reais de sala de aula são como engendramentos de experiências, como espaços aglutinadores de convergências, de sensações, tempos, afetações, como nos ensinou Calvino (1995, p. 119) - produto de percursos, instantes e ações, nunca únicas e sempre múltiplas.

As catástrofes inopinadas não são jamais a consequência ou o efeito, como se costuma dizer, de um motivo único, de uma causa singular: mas são como um vórtice, um ponto 
de depressão ciclônica na consciência do mundo, para as quais conspirava toda uma gama de causalidades convergentes[...]. A opinião de que era necessário "reformar em nós o sentido das categorias de causa” [...] e substituir a causa pelas causas.

As palavras de Calvino nos distanciam de qualquer ideia de alguma plenitude, de uma unidade/identidade determinante e determinista. Seguindo as orientações que ele nos apresenta, podemos avançar naquilo que aparece sempre com muita força nos discursos de formação de professores: a ideia de uma coerência teórico-metodológica nas práticas docentes, em busca de uma identidade profissional. Dito de outra forma, nossos modos de ser são sempre, de alguma forma, momentos de singularizações de multiplicidades, que acabam, porém, sendo capturados por perspectivas identitárias que criam, marcam e modulam perfis e modos de ser professores, a partir dos discursos que constituem lugares para eles e para as crianças.

Dentro do trabalho que temos realizado, a marca daquilo que parece único e identitário está na passagem e no povoamento de alteridades, de "outridades", de diferenças, de sobreposições, de sensações, de sentidos, de corpos e de tempos, migrando, migrantes, migrados, corpos convergindo em subjetividades e em modos de ser. Sendo assim, não importa a tal coerência teórico-metodológica, mas, sim, os contornos do que nisso pode ser percebido.

Na perspectiva da filosofia da diferença, podemos dizer que, para além do discurso e das práticas institucionais, a política pode ser pensada como aquela que produz mundos, através de agenciamentos localizados, uma espécie de "corpo sem órgãos da política, carne viva, que não se deixa totalizar em uma identidade estável, seja ela a massa, a classe, ou o povo" (BRASIL, 2008, p. 6).

Dessa forma, a política cria um campo de ações que não se centra na noção de sujeito, mas de subjetividade. A subjetividade seria, assim, criada, inventada, em agenciamentos parciais, diagramáticos, que articulam elementos semióticos, políticos, tecnológicos, "artísticos. A multitude é o conjunto não totalizável destas subjetividades singulares” (BRASIL, 2008, p. 6).

Como escreve Deleuze, sim, "existem sujeitos: eles são grãos dançantes na poeira do visível, lugares móveis em um murmúrio anônimo. O sujeito é sempre uma derivada. Ele nasce e se esvai na espessura do que se diz, do que se vê" (BRASIL, 2008, p. 6). Ou, ainda, como afirma Agamben (2009, p. 41): "chamo de sujeitos o 
que resulta da relação e, por assim dizer, do corpo a corpo entre os viventes e os dispositivos".

Os deslocamentos, indicados nesta passagem do que chamaremos de pedagogia para as identidades para uma pedagogia em torno das subjetividades apontam também a necessidade de poder pensar a educação e a criança não como únicos e plenos, identitários e determinados, descritos por teorias educativas e psicológicas e demarcados nas políticas públicas, mas como singulares e múltiplos.

O que pode ser pensado a partir disso é que as práticas, que marcam efetivamente a relação adulto-criança, ganharam ao longo do tempo um estatuto em que a diferença - presente nas multiplicidades e nas singularidades - foi tomando a forma de desigualdade e, assim, de inferioridade. Ou seja, o desigual passou a ser inferior, e a diferença, identidade. Nesse caso, a pedagogia tem se constituído como uma pedagogia das identidades, e os dispositivos de inferioridade e de desigualdade criaram a ideia de uma universalidade nos processos e no percurso, ou seja, criaram uma universalidade na Pedagogia e na Psicologia do Desenvolvimento, marcando as práticas de poderes em um invólucro de relações entre superiores e inferiores, entre quem sabe e quem não sabe, produzindo o que Rancière (2004) chamou de uma ordem explicadora e desigual nas práticas educativas.

Assim, diferença passa a ser desvio, deficiência. Por outro lado, se a infância pode ser pensada como diferença, como outro, como menoridade, como estrangeiridade, alteridade, podemos escutar delas as seguintes questões: "Por que vocês pensam que a única língua possível é a sua? Por que vocês pensam que a única roupa possível é a sua? Por que vocês acreditam que a única religião é a sua? E por que querem nos fazer crer que a única música é a que vocês escutam?” (SKLIAR, 2010, p. 153). ${ }^{2}$

Na modernidade, um dos espaços e um dos estatutos de legitimação do modelo das identidades se tornou o discurso da Psicologia e, mais especificamente, da Psicologia do Desenvolvimento e da Educação. A organização de um saber científico e técnico que diz o que e como pensar sobre a infância confirma e dá direção, dentro de um modelo formativo que olha a educação como um lugar já dado, já certo e previsto. Porém, é certo que, por si só, o discurso psicológico não seria suficiente para definir os moldes de uma cultura, embora na convergência de outros

2. Texto em espanhol no original. A tradução foi feita livremente. 
discursos todos eles componham um campo de ações e crenças que define nosso modo de olhar, pensar e sentir a vida.

Não pretendemos aqui nos alongar nessa discussão, mas gostaríamos de evidenciar que esses discursos, de modo geral, acabam por regular práticas com as crianças, capturam certa dispersão das multiplicidades, criando limites ao infinito, suspendendo-o e criando estruturas como referências balizáveis, ou seja, determinam e definem, dentro de um modelo quantificável, as referências do desenvolvimento infantil, como, por exemplo, os estágios de desenvolvimento das crianças demarcado nas estratificações em um tempo cronológico e linear.

\section{INFÂNCIA E IMAGEM}

Nos últimos anos, temos desenvolvido uma série de trabalhos na 'fronteira' entre vários 'territórios'; entre eles, destacamos o cinema, a educação, a infância e o desenvolvimento infantil, que têm nos permitido pensar acerca de alguns temas recorrentes nas preocupações de pesquisadores, de políticas públicas, da escola e dos professores. Definiremos, em um primeiro momento, essas preocupações com questionamentos presentes no cotidiano das escolas de Educação Infantil do município de Rio Claro-SP, onde temos desenvolvido nossas pesquisas. As frequentes perguntas podem ser demarcadas da seguinte forma: Nos trabalhos na Educação Infantil, o que fazer? O que pensar? Para onde ir?

Em que pese que essas questões se apresentam como uma perspectiva muitas vezes instrumentalista, diretiva e com um viés demarcado por uma educação cada dia mais enveredada por perspectivas econômicas de resultados e metas, elas também nos apresentam uma preocupação desses agentes (sejam eles administrativos, burocráticos ou ligados às práticas efetivas de trabalho com as crianças) com os espaços efetivos de trabalhos com as crianças. Parece-nos que as preocupações sempre estão carregadas de um especial olhar para o trabalho efetivo na escola e na sala de aula.

Nessa perspectiva, temos desenvolvido uma série de pesquisas ligadas aos territórios supracitados, e esses estudos têm nos 'convocado' a refletir a partir de uma perspectiva em que crianças e professoras operam como protagonistas em um cenário onde vários agentes atuam; ou seja, nos parece quase impossível pensar no que acontece em uma sala de Educação Infantil, sem colocar em cena todas as questões que tangenciam e tocam o trabalho na escola. Porém, diante 
desse cenário, nossa opção aqui é levantar alguns apontamentos acerca do desenvolvimento infantil, e o faremos a partir de uma série de trabalhos e pesquisas, relativos ao cinema e à produção de imagens, realizados com crianças e professoras de Educação Infantil e com diretoras e coordenadoras de Educação Infantil no município de Rio Claro-SP.

Tomando como ponto de partida algumas dessas iniciativas, temos refletido acerca do poder da imagem e das produções imagéticas realizadas por crianças e professoras dentro dos espaços escolares, e com essas produções temo-nos perguntado: Em um mundo povoado por imagens e por novas tecnologias, o que podemos criar, a partir das sensações que essas imagens nos oferecem? Que imagens da infância podem ser criadas por professores e monitores de Educação Infantil a respeito de seus trabalhos com as crianças, quando a eles oferecemos uma câmera digital ou uma filmadora? Que imagens as crianças de Educação Infantil podem nos oferecer, quando a elas oferecemos uma câmera? Que experiências podem recortar esses diferentes lugares? Que outras lições nós podemos ter com as imagens produzidas em relação àquelas noções de desenvolvimento infantil que povoam e imperam no nosso universo? Que imagens, apresentadas pelas crianças, produzem diferenças com o que usualmente temos, quando nós as filmamos? Que sentidos/imagens podemos oferecer ao estudo do desenvolvimento humano a partir das imagens apresentadas por professores e pelas crianças? Enfim, o que pode a imagem? O que podem nos propor a pensar acerca da educação e da infância crianças e professores com câmeras (fotográficas, filmadoras) e tablets nas mãos?

Guiados por uma metodologia em que entregamos às crianças e às professoras as câmeras digitais e as filmadoras, para a produção de imagens e montagens de enredos e narrativas fílmicas, adotamos a perspectiva de pensar a pesquisa como, conforme a temos chamado, 'experiência - relatos de minorias'. Utilizamos este termo amparados pelas reflexões sobre o conceito de experiência, principalmente no sentido que Giorgio Agamben (2005) apresenta, sobretudo quando vincula o fazer pesquisa a previsões e a processos empíricos definidos.

Pesquisar com crianças e com infância tem se apresentado, em nossos estudos, como abertura e deslocamento de outros tempos e espaços, gerados no circuito de produção de imagens pelas crianças, nas paisagens vertigens, nas imagens sem legendas prévias, nos blocos de sensações onde disparam afectos. O que temos é que as imagens não produzem ou geram um sentido ou sentidos, uma forma ou formas, um território definido de possibilidades para pensar ou para dizer algo certeiro: 
ao assistirmos, aos olharmos as imagens produzidas pelas crianças, elas (crianças e imagens) sempre nos deixam algo em aberto, sempre produzem a sensação de 'já acabou?', sempre ficamos esperando mais. As imagens começam e terminam, fazendo lembrarmo-nos de Benjamin (1994, p. 224), quando diz: "a verdadeira imagem do passado perpassa veloz. O passado só se deixa fixar, como imagem que relampeja irreversivelmente, no momento em que é reconhecido" ou, dizendo de outra forma, as imagens acontecem, nos acontecem e nos passam.

Dessa forma, poderíamos dizer que nem a pesquisa, nem a infância, nem a educação podem ser orientadas, pensadas, conduzidas por um a priori, por um ponto de partida localizado e delineador de pontos de chegadas previamente definidos; nem mesmo podem ser pensadas assim. Mas este trabalho tem nos provocado a pensar uma pesquisa e uma educação atenta, atenciosa ao que se apresente por uma atitude em relação às múltiplas dimensões da infância, em um movimento de invenção recíproca e indissociável da educação e do mundo. A pesquisa com crianças aproxima-nos de uma educação da infância e de uma infância da educação que se abre à aventura, ao desconhecido, à produção do novo, de uma educação inventiva, brincativa, sem função explicativa, descritiva, padronizativa. Essa reflexão que cerca os apontamentos desses trabalhos não se configura como um acaso, mas é, sim, uma escolha definida por aquilo que a própria natureza da pesquisa e da educação nos apresenta: uma perspectiva da 'infância da educação' talvez não possa ser outra que não seja inicial, iniciante, que não traga a perspectiva das incertezas dos percursos da educação e da pesquisa. Uma educação e uma pesquisa que não sejam demarcadas por rotas definidas, dadas a priori, mas que se apresentem atentas ao que acontece.

O que vemos em nossos trabalhos é que os cortes não propositais, mas acidentais, casuais, produto de olhares rápidos, sem técnicas, repletos de perguntas, ecos e sons, deixam-nos a leve sensação de abertura. É como se, ao começar a história e ao vermos os filmes/imagens, ficássemos esperando saber 'o que vem depois'; a infância pela criança apresenta-nos um mundo de reticências, um mundo pontilhado de possibilidades pelo ritmo cortado, sem sentido fixo, sem sentido dado, sem sentido previsto, sem sentido. Mas também esse mundo se apresenta em um tempo povoado por reticências, por ritmos cortados, por tempos não dados, não demarcáveis, por um tempo presente que nos deixa abertura e espera.

É como se houvesse encontros de corpos; é como se a educação criasse a possibilidade de corpos sendo tocados, sendo esbarrados, sendo amputados, 
sendo incorporados pelas próprias imagens e nelas mesmas e pelos próprios equipamentos e neles mesmos; é como se esses possuíssem a força de conduzir e a leveza de serem conduzidos: ganham vida nas mãos e pelos olhares das crianças. É assim que um tablet, muitas vezes, parece operar nas mãos delas: quando vemos um grupo de pequenos guiando e sendo guiados para baixo de uma mesa da sala de aula, quase conduzidos pelas imagens, demarcando territórios que ganham visibilidade nos tablets, observamos imagens por vezes nítidas, por vezes desfocadas ou invertidas. Imagens relâmpagos, instantâneas, longas, com dedos na frente ou babas na tela. Imagens orientadas ou desorientadas, escuras e claras. Escutamos sons, ruídos, risadas, falas. Não são 'sentidos', 'razões', 'lógicas', que vemos presentes ali. $\mathrm{O}$ que vemos são crianças brincando com nossos sentidos, nossas razões e nossas lógicas, crianças produzindo, em nós, blocos de sensações em que operam deslocamentos de espaços e tempos, 'criando', no tempo das imagens, momentos 'críticos', transitórios e povoados de oportunidades, como um tempo kairológico, mas também algo que parece profanar as expectativas de um passado, um presente e um futuro e cria povoamentos de intensidades e temporalidades não quantificáveis, numeráveis.

É como se aquilo que frequentemente está presente em nossos discursos, nas 'formas discursivas' com que convivemos nos discursos científicos, amparados muitas vezes nas políticas públicas para a educação, fosse 'anarquizado' por um coletivo de quatro ou cinco crianças que correm para baixo da mesa, experimentando com as camerascorpos possibilidades outras para seus corposcâmeras; ou como se, simplesmente, por serem um coletivo, implodissem a ideia de homogeneidade das massas, dos grupos identitários, muitas vezes presentes nas perspectivas lineares e cronológicas de várias teorias de desenvolvimento infantil.

É como se o coletivo de crianças, que, ao saírem de baixo da mesa, se dissipassem em novos coletivos, ocupando novos espaços e nos colocando diante de outras possibilidades; como se perguntassem à educação sobre suas normatividades, sobre suas diretrizes, seus propósitos. As crianças não parecem negar essas normatividades, diretrizes e propósitos, parecem apenas nos perguntar sobre eles.

As crianças exploram com seus corpos e pela coletividade os espaços da educação, sempre nos perguntando sobre a própria educação. Parece que elas incluem, nos seus modos de ocupação de espaços, uma ideia de multiplicidade. Gilles Deleuze (2011a) nos apresenta sobre esse tema uma discussão que pode abrir algumas 
possibilidades de reflexão. Ao discutir sobre multiplicidade, Deleuze retoma uma reflexão apresentada por Elias Canetti. Comecemos pela discussão sobre massa.

Canetti distingue dois tipos de multiplicidade que às vezes se opõem e às vezes se penetram: de massa e de matilha. Entre os caracteres de massa, no sentido de Canetti, precisa-se notar a grande quantidade, a divisibilidade e a igualdade dos membros, a concentração, a sociabilidade do conjunto, a unicidade da direção hierárquica, a organização da territorialização, a emissão de signos. (DELEUZE, 2011a, p. 60).

De um modo geral, nas práticas educativas e nas 'ordens discursivas' dentro e fora da escola, vemos imperar essa perspectiva do que Gilles Deleuze, a partir de Canetti, chama de "massa". Na Educação Infantil, esses pressupostos têm sido determinantes, pois, apesar de observamos, muitas vezes, certo distanciamento dos discursos de uma proposta conteudista com as crianças pequenas, vemos com frequência emergir das práticas, das políticas públicas e das orientações teóricas uma proposta vinculada e uma periodização do desenvolvimento infantil, e esta, por sua vez, acaba determinando formas de lidar com a criança e de pensar a infância.

Nesses discursos orientados por um modelo de respeito ao processo de desenvolvimento infantil, na prática o que ganha força é uma perspectiva em que a criança é colocada em um tempo, um tempo determinado por certa periodização, um tempo das rotinas, um tempo das propostas e dos propósitos da educação.

Essa mesma perspectiva acaba, por vezes, sendo determinante das práticas não só com as crianças, mas também com os próprios professores, pois é vigente, nas ações formativas dos docentes, uma ideia identitária de papel e de perfil do professor, presente nas falas e nas posturas que ele assume. É perceptível também que, nessas práticas, eles acabam sendo orientados a pensar no seu trabalho com as crianças dentro de modelos em que reinam a "quantidade, a divisibilidade e a igualdade dos membros, a concentração, a sociabilidade do conjunto, a unicidade da direção hierárquica, a organização da territorialização, a emissão de signos" (DELEUZE, 2011a, p. 60). Não é nosso propósito aqui negar essas questões, pois elas nos parecem ser marcantes nas experiências educativas e por isso se manifestam como modos presentes nas formas de existência da criança, mas o que pretendemos é problematizar o fato de serem, muitas vezes, o único modo de pensar o trabalho na Educação Infantil. 
Outra temática trazida por Deleuze (2011a, p. 60-61), a partir de Canetti, nos fala da matilha:

Entre os caracteres da matilha, a exiguidade ou a restrição do número, a dispersão, as distâncias variáveis indecomponíveis, as metamorfoses qualitativas, as desigualdades como restos ou ultrapassagens, a impossibilidade de uma totalização ou de uma hierarquização fixas, a variedade browniana das direções, as linhas de desterritorialização, a projeção de partículas. [...] A matilha, mesmo em seus lugares, constitui-se em uma linha de fuga ou de desterritorialização que faz parte dela mesma, linha a que ela dá um elevado valor positivo.

As imagens das crianças, corpos-espaços-tempos, nos oferecem formas de ocupação dos espaços por elas na escola, pois vemos corpos que se misturam com os próprios equipamentos, corpos pulsando e sendo pulsados, sendo confundidos. Corpos que rompem com lugares e formas fixas, gerando verdadeiras metamorfoses que rompem com a rigidez de certas hierarquizações de tempos e espaços. Pois o que podemos observar não é que as crianças entram embaixo da mesa para filmar algo específico ou tomar um ângulo determinado para uma cena: o que vemos são crianças, corpos, 'corposcriança', corpos criançando e explorando os espaços e os territórios da sala de aula e da escola, produzindo, assim, desvios, rotas, linhas de fugas aos processos de massificação e de modulação da infância e da criança.

Não nos parece que as crianças se "empoderam" dos equipamentos, mas, sim, que se misturam com eles e acabam sendo guiadas por sutilezas afetivas e contagiantes, pois o mesmo grupo que, por segundos, fica embaixo da mesa, logo sai e se dissolve, sempre mobilizado por um outro equipamento, um grito, uma formiga que aparece em algum espaço da sala. Ao produzirem esses movimentos, criam novos coletivos, apresentam novas linhas e nos convidam a pensar sobre aquilo que, entre outros aspectos, orienta muitas das práticas educativas na Educação Infantil.

Demarcamos aqui um ponto importante, pois não são novos modos, muitas vezes presentes, de pensar a infância e a criança que estamos procurando trazer aqui; não é a infância como esse lugar romanceado por discursos e práticas com as crianças tão frequentes hoje em dia - estamos aqui falando de um 'devir-criança', como apresentado por Deleuze (1997, p. 129) em Crítica e clínica: 
A obra gaguejante de Biely, Kotik Letaiev, lançada num devir-criança que não é eu, mas cosmos, explosão de mundo: uma invenção que não é a minha, que não é uma recordação, mas um bloco, um fragmento anônimo infinito, um devir sempre contemporâneo.

Ao falar das unidades da língua, Gilles Deleuze (2011b) nos diz que ela é, antes de tudo, política:

Não existe língua-mãe, e sim tomada de poder por uma língua dominante, que ora avança sobre uma grande frente, ora se abate simultaneamente sobre centros diversos. Podem-se conceber várias maneiras de uma língua se homogeneizar, se centralizar: a maneira republicana não é necessariamente a mesma que a real, e não é a menos dura. (DELEUZE, 2011b, p. 49).

Caminhando um pouco mais nesta discussão, Deleuze nos diz que seria preciso distinguir dois tipos de línguas: “altas” e "baixas”, maiores e menores,

Umas [as altas] se definiriam justamente pelo poder das constantes, outras [as baixas], pela potência da variação. Não queremos simplesmente opor a unidade de uma língua a uma multiplicidade de dialetos. É, antes, cada dialeto que se encontra afetado por zona de transição e de variação, ou melhor, é cada língua menor que se encontra afetada por uma zona de variação propriamente dialetal. (DELEUZE, 2011b, p. 50).

Na mesma direção com que Deleuze fala de uma língua menor, Gallo (2008) também nos apresenta uma perspectiva de uma possível "educação menor". Tomando como pressuposto a obra de Gilles Deleuze e Felix Guattari, Kafka - por uma literatura menor, Gallo (2008) nos posiciona sobre a possibilidade de pensar, como dispositivo, uma noção de uma educação menor. Não nos interessa aqui, neste momento, aprofundar esta discussão. O que nos propomos a fazer é: trazendo esta discussão e, diante do que as crianças oferecem, com seus corpos e modos de ocupação dos espaços escolares na educação infantil, não poderíamos pensar outras potências do tempo, outras temporalidades nos processos de desenvolvimento infantil e no próprio desenvolvimento humano?

Ou ainda, como ensina Lyotard (apud GAGNEBIN 1997, p. 99), “[é] porque a in-fância não é humanidade completa e acabada, é porque a in-fância é, [...] in-humana, que, talvez, ela nos indique o que há de mais verdadeiro no pensamento 
humano: a saber, sua incompletude [...]”. Dessa forma, a infância revela para nós o que somos e o que a todo custo tentamos esconder: seres incompletos e inacabados.

Quase como um convite a olhar para a infância e para a própria vida, as imagens rápidas, 'de passagens', cortadas e entrecortadas nos sugerem outra possibilidade de pensar no tempo, não mais em um tempo repetitivo, nem tampouco linear e contínuo, mas um tempo que, sendo 'curto', dura. A duração parece estar naquilo que ele produz, na inquietude que ele dispara, no mal-estar e na necessidade de ter que dizer algo, nas afetações que essas imagens produzem. Ou, como nos apresenta Deleuze (2007, p. 28), falando sobre a natureza morta, "cada uma é o tempo, cada vez, sob estas ou aquelas condições do que muda no tempo. O tempo é o pleno, quer dizer, a forma inalterável preenchida pela mudança. $\mathrm{O}$ tempo é a reserva visual dos acontecimentos em sua justeza”.

As imagens produzidas pelas crianças são quase tão rápidas como uma imagem fixa turva e desfocada, tão superficiais. Não são profundas, não produzem sentidos, mas tocam a pele, cortam, suavizam, embaralham, confundem. Poderíamos aqui encontrar um retrato da infância, apresentado pela própria imagem como

[...] um lugar angustiante, onde o fôlego está suspenso como se, abandonado pelas palavras, apagasse nas noites do impensado; lugar feliz onde o fôlego renasce como ao retornar-se a respiração para aventurar-se a um novo caminho, em direção a novas palavras, à prova de um novo verso. (GAGNEBIN, 1994, p. 118).

Nesses modos apresentados pelas crianças, podemos pensar alguns caminhos e sendas para relações entre tempo e experiências infantis, que se apresentem em outra noção de tempo e de experiência, não mais um tempo vazio, mas um tempo que escapa e do qual não conseguimos falar - apenas experimentar -, que foge à palavra, à razão e cria a experiência, "[...] permite pensar o Evento não mais como uma determinação espaciotemporal, mas como a abertura da dimensão originária sobre a qual se funda toda dimensão espaciotemporal” (AGAMBEN, 2005, p. 127).

Pois, mesmo que saibamos da presença de uma infância que se apresenta como continuidade cronológica, como uma das fases do desenvolvimento (os bebês, a infância, a adolescência, a vida adulta e a velhice), a infância que aprendemos a educar desde os gregos, que ocupa os discursos das escolas e nas escolas, nas políticas. E, embora não neguemos essa infância/criança, constatamos, a partir do trabalho de produção de imagem que desenvolvemos, tanto em creche como em pré-escola, que 
[...] existe também uma outra infância, que habita uma outra temporalidade, outras linhas: a infância minoritária. Essa é a infância como experiência, como acontecimento, como ruptura da história, como revolução, como resistência e como criação. É a infância que interrompe a história, que se encontra em um devir minoritário, numa linha de fuga, num detalhe. Infância que se resiste aos movimentos concêntricos, arborizados, totalizantes: “a criança autista”, “o aluno nota dez", "o menino violento”. É a infância como intensidade, um situar-se intensivo no mundo, um sair sempre do "seu" lugar e se situar em outros lugares, desconhecidos, inusitados, inesperados. (KOHAN, 2007 p. 94-95).

\section{REFERÊNCIAS}

AGAMBEN, Giorgio. Infância e história: destruição da experiência e origem da história. Belo Horizonte, MG: Editora UFMG, 2005.

AGAMBEN, Giorgio. O que é o contemporâneo? E outros dispositivos. Chapecó, SC: Argos, 2009.

BENJAMIN, Walter. Obras escolhidas I: magia e técnica, arte e política. São Paulo: Brasiliense, 1994. BRASIL, André. Modulação/Montagem: ensaio sobre biopolítica experiência estética. Tese (Doutorado) - Programa de Pós-Graduação em Comunicação, Faculdade de Comunicação, Universidade Federal do Rio de Janeiro, Rio de Janeiro, 2008.

CALVINO, Italo. Seis propostas para o próximo milênio. São Paulo: Companhia das Letras, 1995.

DELEUZE, Gilles. Crítica e clínica. São Paulo, SP: Editora 34, 1997.

DELEUZE, Gilles. A imagem tempo - cinema 2. São Paulo, SP: Brasiliense, 2007.

DELEUZE, Gilles. O que é a Filosofia. São Paulo, SP: Editora 34, 2010.

DELEUZE, Gilles. Mil platôs. São Paulo, SP: Editora 34. 2011a. v. 1.

DELEUZE, Gilles. Mil platôs. São Paulo, SP: Editora 34. 2011b. v. 2.

FOUCAULT, Michel. Microfísica do poder. São Paulo, SP: Graal, 2009.

GAGNEBIN, Jeanne M. História e narração em W. Benjamin. São Paulo: Perspectiva, 1994.

GAGNEBIN, Jeanne M. Sete aulas sobre linguagem, memória e história. Rio de Janeiro: Imago, 1997. GALLO, Silvio. Deleuze e a Educação. Belo Horizonte; Autêntica, 2008.

KOHAN, Walter. Infância, estrangeiridade e ignorância. Belo Horizonte, MG: Autêntica, 2007.

LEITE, César Donizetti Pereira. Labirinto: infância, linguagem e escola. Taubaté, SP: Cabral Editora Universitária, 2007.

RANCIÈRE, Jacques. O mestre ignorante. Belo Horizonte, MG: Autêntica, 2004.

SKLIAR, Carlos. Fragmentos de experiencia y alteridad. In: LARROSA, Jorge; SKLIAR, Carlos. (Ed.). Experiencia y alteridad en educación. Rosário, Argentina: Homo Sapiens Ediciones, 2010. p. 143-16o.

SKRAMIN, Sônia; HONESKO, Vinícius. Apresentação. In: AGAMBEN, Giorgi. O que é o contemporâneo? Chapecó, SC: Argos, 2009. p. 07-22. 
SOBRE O AUTOR

César Donizetti Pereira Leite é graduado em Psicologia (Pontifícia Universidade Católica de Campinas), tem Mestrado e Doutorado em Educação (Universidade Estadual de Campinas) e dois Pós-Doutorados (FLACSO - Argentina; Universidade Complutense de Madrid - Espanha). É Livre-Docente (UNESP). É Professor Adjunto da Universidade Estadual Paulista "Júlio de Mesquita Filho". Tem experiência na área de Psicologia e Educação, com pesquisa nos seguintes temas: educação, infância, cinema e produção de imagens.

E-mail: cesar@rc.unesp.br ou mvhleite@uol.com.br

Recebido em 21 de novembro de 2016 e aprovado em 15 de dezembro de 2016. 